\title{
THE DESIGN OF FOUR-CYCLE PETROL AND PARAFFIN MARINE MOTORS FOR UTILITY PURPOSES.
}

By COLIN H. MACMTLLAN, B.Sc.

UNDER the above title the author proposes to discuss the features of design of inboard marine motors of the four-cycle type intended for purposes of utility as opposed to those specially used for racing, dealing with the subject more especially from the point of view of accessibility and ease of operation. He does not intend to discuss marine motors of the larger sizes, but to confine himself to those ranging up to about $100 \mathrm{~h} . \mathrm{p}$.

The features which it is desirable to incorporate in a marine motor vary to a certain extent according to the class of boat in which it is to be installed, but a great many are desirable in all types of boats which are suitable for engines of the size under consideration. The desire of all users is to have an engine which is absolutely reliable, which is economical in fuel, lubricating oil and repairs, which oceupies little space, which requires a minimum of attention and which possesses as few objectionable features as possible, such as smell, excessive heat, vibration, noise, etc.

It is impossible to design an engine which will give the user all the desirable features with none of the undesirable ones, but it is the duty of the designer to balance the advantages and disadvantages in such a way as to give the user the compromise which most nearly meets with his approval. This is no easy matter, and is one on which opinions vary very widely. It is further complicated by the fact that the vessels into which marine motors are fitted are of a vast variety of types, while on the manufacturing side of the question the designer must keep before him the fact that the wider the range of use of any one design the cheaper will its manufacture become.

The vast majority of small marine motors are tended by totally unskilled men and have little opportunity of coming under the care of expert mechanics as is the case with motor vehicles. It therefore becomes a matter of very great importance that the motor should be sufficiently simple to operate and sufficiently durable that it will be able to work satisfactorily over very long periods without the necessity of an overhaul by skilled engineers. It should also be constructed in such a way that any small troubles which are likely to be encountered can be rectified by an inexperienced person if he follows a few simple instructions. It must always

$16(2)$ 
be borne in mind that, human nature being what it is, the less that requires to be done to an engine to maintain it in an efficient condition the more likely. it is that it will be maintained in that condition.

The efficiency of an engine should be judged by the amount of service it renders in exchange for the total value put into it. By "the total value put into" an engine is meant not only initial cost plus the value of fuel, oil, repairs, replacements and overhauls, but also the labour incurred in running the engine and in looking after its wants. Even when the engine is privately owned the labour of running and maintaining it in a proper state must be taken into account. Frequently under such conditions a considerable increase in other expenses would be welcomed if at the same time much of the trouble were eliminated. Similarly, it may also be found that an engine which is extravagant in fuel and oil may be more economical to run if it is exceptionally simple to operate and thus avoids the necessity for employing highly skilled drivers. When efficiency is understood in this light it will be found that simplicity of operation and maintenanee must be one of the prime aims of the designer.

In order that the maintenance and operation of an engine may be made as simple as possible it is essential that all parts which require attention by the driver should be readily accessible. Accessibility must be considered from two points of view, that of the manufacturer or repairer, and that of the driver. The latter is in the author's opinion vastly more important than the former.

Accessibility from the point of view of the manufacturer or repairer is of considerable importance to the user in that it probably reduces the cost of the engine in the first instance, and the cost of overhauls and repairs when in service. It is, however, of much greater importance to the user that those parts which require regular attention or possibly require attention as the result of an accident or breakdown at sea should be quickly accessible in order that the necessary adjustments or repairs may be effected with the least possible loss of time. The speed with which temporary. repairs can be executed under. such conditions may mean the saving of the boat and possibly the lites of those on board. The author therefore proposes to consider accessibility more especially from the point of view of the user.

In all motors except those of the smallest sizes the parts should be arranged so that they ean be built up commencing with the bedplate or bottom half of the crankcase. This method of construction enables the machinery to be built up in position and aroids the necessity for lifting the whole engine, or at least the whole crankcase, into position in one piece. The bedplate should be so made that it can be supported on longitudinal bearers of as deep section as passible in order that the weight of the machinery may extend over as many of the frames of the boat as possible. If a reverse gear or reducing gear is fitted this should 
be incorporated in the engine bedplate in order to increase, as far as possible, the stiffness of the complete unit, and eliminate undue bearing pressures due to twisting of the bed. This has the further advantage of considerably reducing the vibration caused by the engine. Much discussion, has taken place in the past on the merits of the open crankpit, but for engines of the type we are considering there is little doubt that the advantages of the totally enclosed crankcase far outweigh those of the open crankpit. This point will be mentioned later in connection with other features of design.

The main bearings should be split along their horizontal centre line and have separate caps fitted on the top. This is a very essential feature, as it enables bearing adjustments to be made without removing the top half of the crankcase. In order that this may be carried out, it is of course necessary to have sufficiently large inspection doors on both sides to enable spanners, etc. to be manipulated.

The bearings should be of white metal and fitted with shims to facilitate adjustment. Die-cast white metal bearings have come into considerable use in marine motors, and, in the author's opinion, they possess advantages from the user's point of view which undoubtedly justify their adoption in preference to gunmetal housings lined with white metal. The principal advantages are their low initial cost and the facility with which they can be fitted, and the fact that it is much cheaper to replace a die-cast bearing than to reline a gun-metal housing. Their principal disadvantage is that in the event of a bearing being completely. run out it is a diffioult matter to replace it if no spare is available, but, as already mentioned, they are low in initial cost, and spares ought to be carried.

The crankpin bearings can with great advantage be made interehangeable with the main bearings, and if these be of die-cast white metal the weight of the big end of the connecting rod can be considerably reduced, thus lessening the inertia forces and the bearing pressures. The size of the crankpin' and main bearings should be such that the engine is capable of running with the throttle full open for hours or days on end without injury to its boarings. In this connection it is necassary to consider whether there should be a main bearing between each conseeutive orankpin or between each consecutive pair of crankpins.' The length of the main and crankpin bearings and the thickness of the crank webs are the principal measurements which determine the overall length of the engine, and if space is valuable the overall length must be kept down as far as possible. By fitting one main bearing between each consecutive pair of crankpins and casting the cylinders in pairs, it is possible, without increasing the overall length of the engine, to employ longer bearings than when a main bearing sitfited between each consecutive crankpin. It is true that the redneed number of bearings involves considerably longer spans 
between them, but this can be compensated for (so far as the strength of the shaft is concerned) by a very small increase in the shaft diameter, and this allows of a still further increase in the bearing surface. This design also facilitates the making of all main bearings interchangeable with each other and with the bigend bearings, and it also increases considerably the accessibility of the main and big-end bearings, as owing to the greater distance between the main bearings, it is possible to swing spanners through greater angles.

In connection with the design of the cylinder, a very great diversity of opinion exists in regard to the placing of the valves and as to whether the heads should be detachable or cast solid. In a marine motor, more especially in the larger sizes, the detachable head imparts advantages which, in the author's opinion, outweigh the disadvantages. For instance, the decarbonising of the combustion chamber and valves is facilitated, not only on account of the greater ease of handling the small weight of the head, as compared with that of the complete cylinder casting, but also on account of the better access to the seat of the trouble which is thus obtained. The detachable head shows to great advantage when the engine is installed in a position which allows only a small amount of head room over it, under which conditions the removal of the heavy cylinder is a task of considerable difficulty. By making the task of decarbonising the combustion chamber and piston head simpler, higher compression pressures may be employed, as decarbonisation will be carried out more frequently owing to the simplicity of the job. In an engine fitted with detachable heads the combustion chamber can be thoroughly cleared of every vestige of carbon, whereas in some non-detachable-headed cylinders it is practically impossible to reach some of the parts. The detachable head also allows the piston and connecting rod to be withdrawn without removing the cylinder itself. The removal of a detachable head can be made a very simple matter if the piping and valve gear are carefully planned. If the valves and valve gear are mounted entirely on the cylinder itself, the necessity for disconnecting the inlet or exhaust manifolds in order to remove the heads is avoided, and only water connections and possibly the sparking plug wires have to be taken adrift. The water connection to the head may, however, be arranged as part of the cylinder-head joint. The water joint between the cylinder and the head may be made in a variety of ways. A copper and asbestos gasket is employed in some engines, but under such conditions there is a possibility of water reaching the asbestos and ultimately saturating it, when it will probably be blown out, thus causing a leak which can only be cured by fitting a new gasket. The asbestos can, of course, be protected by rolling the copper right over it at the water space, but the corrosive action of sea water on the cylinder and head at this point will ultimately roughen and pit the surface and prevent a good joint being made. These troubies 
can be eliminated by fitting a deep rubber ring joint, independent of the gasket, which is compressed against corresponding recesses in the faces of the cylinder and the head, thus making a separate water joint. In some engines a separate rubber joint is made between two extension elbows outside the main joint. Either of those two methods attain the object of preventing water softening the asbestos of the pressure joint without increasing the difficulty. of removing the head. An objection is sometimes raised to detachable cylinder heads on the score that the valves are more inaccessible than when caps are fitted over each valve, but, provided that the detaching of the cylinder can be effected simply and rapidly, there is little in this. On the other hand, the absence of the separate caps eliminates the hot spots which are inseparable from any parts which are not water cooled. It is, however, essential that in order to secure the very real advantages of the detachable head, the operation must be rendered as simple as possible by making all the securing nuts accessible and the water outlet connection easily removable and by avoiding any possible obstructions.. When the valves are mounted on the cylinder head the difficulties and the work involved in removing the head are increased to an extent which is not warranted by the advantages of such a construction.

Whilst on the subject of cylinders, it might be well to say a few words regarding their cooling. It is most important that the jackets should be designed so that every part of the cylinder barrel, the combustion chamber and the exhaust passages are efficiently. cooled, and that the water circulates freely all round these parts without forming air or steam pockets; at the same time the jackets must be fitted with doors or other means by which any sediment may be cleared out, as no matter how efficiently the water may be strained sediment is liable to accumulate in the jackets.

The author is of opinion that the plunger pump is by far the most suitable type for a marine motor. If it has to be installed above the water level it can be relied on to lift the water with much greater certainty than a gear or vane pump, and even when a considerable amount of wear has taken place it will continue to work satisfactorily, whereas either of the other two types would no longer do so. The water strainer should not be fitted outside the hull where it cannot be cleaned whilst atloat. The water intake should come straight through the skin of the boat, through the seacock and then into the strainer, and should be so arranged that in the event of the intake becoming choked a rod can be pushed through from inside the boat to clear the obstruction. The strainer should be capable of being inspected and, if necessary, cleaned whilst the engine is running.

Practically all engines of the type under consideration have their valves operated by cams. The tappets or slippers which transmit the motion from the cams to the valves should be fitted with rollers, which greatly lengthens the life of the cams. The design of the valves themselves is of great importance, but if due care is given 
to the problem, and if they are made from suitable material, little trouble should be experienced from this source. In moderate-speed engines, valves having cast-iron heads and steel stems give excellent results, provided the heads are securely fixed to the stems; they require exceptionally little attention, as the cast iron of the head withstands prolonged use without pitting or distortion. The author has had considerable experience with this type of valve, and knows of many cases where engines have been running for periods of some years in regular commercial work without the valves having been even examined. The valve stem guides should invariably be bushed, so that they may be replaced when worn.

Most petrol marine motors are now fitted with carburettors made by one of the firms specialising in their manufacture, and there are a considerable number to choose from to suit each case. For marine use, a very simple carburettor should be chosen; the fewer adjustments that are possible the more reliable is it likely to be. The carburettor must also be readily accessible for examination and cleaning or adjustment, and if all jets and passages cannot conveniently be cleaned with the carburettor in position, it must be made readily detachable.

In paraffin motors, probably no single feature varies more widely in design than the vapouriser, yet this is the heart of the engine and is more directly responsible for fuel economy, power and flexibility than any other single part. The construction of a paraffin vapouriser which will do all that is required of it is a very much more complex problem than that of a petrol carburettor, and the result is that it has not quite reached the same degree of perfection. In the author's opinion, it should be able to give reasonable flexibility without sacrificing other properties, and a paraffin motor should at least be able to run at less than one-third of the normal speed when driving the propeller, and for an indefinite period without load, without employing special expedients such as switching over to petrol or lighting up lamps.

Accessibility in a petrol carburettor is important, but in a paraffin vapouriser it is much more so, and the vapourising chamber must be so designed as to be easily examined or cleaned; unfortunately, owing to the heat to which this part is subjected, the problem is no easy one, and whatever the solution new joints or packings will probably have to be fitted. Complicated shapes in the vapourising chamber also must be avoided both inside aind outside, so that deposits of tar or carbon can easily be removed.

The efficient lubrication of all working parts is a matter of prime importance in a marine motor, especially on those which are called upon to work for extended periods on full load. Every system of lubrication to be really satisfactory must be so designed as to require a minimum of attention on the part of the driver, otherwise it is almost certain to be neglected and the engine will suffer as a result.

The principal means of distributing oil are: (a) gravity, 
(b) splash, (c) force pump and (d) a combination of two or more of these.

Under the heading (a) is included the tank with drip-feeds to the various bearings. This system has the advantage of simplicity, and is easily comprehended by the meanest intelligence, but it has the disadvantages of requiring constant attention in the adjustment of the drip-feeds to the requirements of the moment. It is also very easily put out of order by the choking of any of the pipes or adjustable valves, and by variations in temperature or the quality of the oil.

There are many engines which may be said to work purely on: the splash system, which again has the great adrantage of extreme simplicity. In its original form this system is most unsuitable for a marine motor, but some modern developments have made it much more practicable. When splashers, fixed to the connecting rod big ends or to the crank webs, are employed to splash the oil about inside the crankcase, it is very important that the shape of the wells into which the splashers dip should be such that the lubrication is not seriously affected by the rolling or pitching of the boat through any reasonable angle or by the engine being raked up to 1 in 6 , and also that all the splashers should have a similar amount of dip. All the bearings should be fitted with receptacles to collect oil, and from these one or more oil holes should feed the bearing. The methods employed to maintain a constant level of oil in the wells vary very widely, but the majority depend upon some form of ducts fitted to the crankcase or cast integral with it which carry the oil to a well at the forward end, from which any excess orerflows to the next one aft. Unless some special provision is made, however, a good deal of care is required on the part of the driver to maintain the oil at a sufficiently constant level to prerent over-oiling or starving of the after end of the engine.

In the force-feed system oil is drawn by a pump from a sump and is forced to the main bearings, and possibly other parts, the connecting rod big-end bearings being fed by the excess of oil from the main bearings either by holes drilled through the crankshaft, or by collector groves, such as banjos fixed to the crankwebs. In some cases a sight-feed drip in some form is added in order to allow the driver to keep the feed to each point under observation, while in others a separate adjustable pump delivers fresh oil to each individual point. Except in the latter case, am oil filter is usually fitted as part of any pump system.

In very few engines is the gravity system employed by itself, but it is sometimes used in conjunction with a circulating pump to keep the tank full, and a pump is also frequently employed with the splash system. It then becomes possible to maintain the oil below each splasher at a constant level by pouring an abundant supply of oil into each well or trough, any excess overflowing into the sump from which the pump draws its supply. A modification 
of this system is to use the fly wheel to circulate the oil, and so avoid the necessity for a pump. The flywheel dips into the oil in the sump and throws it into collecting buckets placed above it, from which the oil flows to the main bearings and timing gear through large bore pipes, the excess oil pouring into the oil wells below the connecting rods, and maintaining a constant level as in the pump and trough system. This is really a purely splash system, unless the flywheel is considered as a pump, but it has the advantage that the oil can be filtered while being circulated, so that the bearings are always supplied with clean oil.

In discussing the advantages and disadvantages of the different systems of lubrication for small marine motors, the feature which is of greatest importance is reliability. Any system may be excellent whilst working, but if it is liable to cease operating its value must be proportionately diminished.

The force-feed system probably gives the best lubrication whilst in perfect condition. In engines in which it is impossible to avoid very large bearing pressures it is practically the only system which can be used. It has, however, many weaknesses. The pump, for instanee, may cease to act for some reason, and the indicator, which is usually fitted to show whether the pump is doing its duty or not, may not be observed in time to prevent damage, while the indicator which merely indicates pressure and not flow of oil is positively dangerous, as if the delivery pipe from the indicator to the bearings be choked the indicator will still show pressure, though no oil is reaching its destination. In engines in which the crankpin bearings are supplied with oil under pressure from the main bearings through holes drilled in the crankshaft, it is essential that the main bearings be a good fit, otherwise the oil is liable to leak out of the main bearings and not reach the big-end bearings at all. Beyond this, if any one passage in the system becomes choked, as may easily happen by a bearing becoming overheated and filling its supply hole with white metal, the oil supply to that bearing, and possibly to others, will be completely cut off, with disastrous results. Another weakness in this system is that in the event of a breakdown of the pump, the engine cannot be efficiently lubricated by filling up the crankcase with oil and trusting to splash, owing to the fact that the bearings have no feed holes or ducts to oollect the oil.

A splash system of lubrication in which the oil supply is properly regulated by pump or other means offers many advantages over all other systems, and, in the author's opinion, provided that the necessary care is given to its design, the flywheelcirculated trough system is the most suitable for the type of engine which we are considering. It is a simple matter to employ pipes of as large a bore as half an inch to convey the oil from the collecting buckets to the bearings, and these practically cannot become choked. It is, however, advisable that there should be some means of ascertaining whether the oil is flowing in the 
pipes or not, either by fitting sight-feeds or test cocks. There is a limit, of course, to the height at which the collecting buckets can be placed, but this can easily be arranged so that the engine may be installed at a rake of 1 in 6 without interfering with the cireulation of the oil. If the splashers are intended to be direct feeder-ducts for the big-end bearings, it is better to have them forged integral with the big-end bearing cap in order to avoid any risk of their coming loose or turning to face in the wrong: direction. The big-end bearings should also have oil holes on their upper side, from which they can receive an oil supply in the event of the main supply duct becoming choked. Such a system will only fail completely if all oil supply is cut off owing to the pump ceasing to work or one of the main supplies to or from the pump becoming choked. It will continue to work by splash so long as oil is being circulated, and should the circulation fail the addition of oil to the crankcase up to such a level as will allow one or two of the dippers to reach the oil, the engine in most cases will be sufficiently well lubricated to enable the boat to reach port. By the employment of the flywheel to circulate the oil in place of a pump, and fitting a separate collecting bucket and feed pipe for each main bearing, the chances of total failure are very much reduced, though the system does not, of course, give so much pressure as a pump.

In engines which depend on a pump for lubrication, the pump must be so arranged as to be quickly removable for examination or repair, and this must be done without draining the oil from the sump.

The same may be said of the oil filter, and it is a considerable advantage if this can also be examined and cleaned whilst the engine is running.

By totally enclosing all working parts, such as timing gears, camshafts, tappets, valve springs, etc., these can all be efficiently, Iubricated from the crankcase proper, and at the same time the noise of the gears, tappets, etc. is much reduced. The fewer points there are which require individual attention with the oilcan the better, the ideal being an engine in which there is only one oilfilling hole.

High tension magneto ignition is now very nearly universal in this type of motor. If properly cared for it is very reliable, but to the very great majority of drivers the magneto itself is a pure mystery box, and the proper timing of it a veritable nightmare. Though it is impossible for the designer to eliminate the difficulties which the user sees in working with a magneto, it is his duty to simplify, as far as possible, the work connected with it. It must be placed in a position which is, as far as possible, free from spray or bilge water, and it must not be placed too near hot exhaust pipes or vapourisers. It must also be immediately accessible for examination, cleaning or adjustment without the necessity of removing it from the engine. The driving coupling should be 
as simple as possible and arranged so that there is a minimum number of wrong ways of replacing the magneto when it has been removed. Vernier couplings are becoming more common, but to some drivers this is merely making confusion worse confounded.

The wires from the magneto to the plugs should be run in such a way that they can easily be traced out and replaced individually if required.

Battery and coil iguition is frequently fitted as a standby, and also to facilitate starting. Owing to the neglect to which the battery is usually subjected, this system is, on the average, very much less reliable than the magneto, and when it is reguired owing to the failure of the magneto, it is very often found to be out of commission. In the author's opinion, a spare magneto is a more useful standby than a coil and battery.

Impulse starting couplings are coming into use to facilitate the starting of engines fitted with magneto ignition, but these have yet to prove their reliability when in constant use in motar boats.

Within the limits of this paper it has been impossible to discuss all the features of design which might have been desired, but the author has endeavoured to include the more important points which have a direct bearing on the utility of the marine motor from the user's point of view, and in so doing he hopes that some points of controversy have been raised which will lead to a aseful discussion. 


\section{THE DISCUSSION.}

The President: The subject of marine engines is a very wide one, and the author has wisely limited himself to certain aspects and to engines up to 100 h.p. There are, of course, many other aspects-also of great importance. The question of the dilution of lubricating oil due to the leakage of paraffin past the pistons might alone form the subject for a discussion lasting several hours, and it is hard to know where to take the dividing line.

Mr. O. W. J. Watson, in opening the discussion, said: One point that I think the author has not laid enough stress on is the fact that the marine engine is a special study of its own. In the past too many people have taken an automobile engine, ardded a gear pump and one or two other details, and sold it as a marine engine for an extra price of, say, $£ 30$ or $£ 40$. The chief point in the elimination of vibration is the design of the crankshaft. A small crankshaft with overloaded bearings will undoubtedly cause vibration. It will also be the cause of noise, chiefly in the gears, and wear. After considerable experience I have come to the conclusion that white-metal die-cast bearings are not the best. I do not think there is anything to touch a gun-metal or phosphorbronzo shell lined with white-metal. The white-metal should not be more than, say, 1/16 in. thick. I have found in practice that die-cast bearings without a shell will, after six or twelve hours' test, become extruded. I think that detachable beads are quite essential with marine engines of anything over 5 or $6 \mathrm{~h}$.p., because, as the author points out, it makes the removal of carbon a very. much easier and more convenient process. It is almost impossible to avoid leaving 10 or 20 per cent of the carbon behind in the case of a cylinder block without detachable heads, and it has to be decarbonised again very shortly. With regard to cylinder head gaskets, I have tried the separate rubber joint, but it is not quite so easy as it appears at first sight. To'make a joint with two materials is a distinctly difficult proposition, especially for the amateur. In this connection, the question of making the joint depends entirely on the manufacture of the gasket itself. In this country, I am sorry to say, the majority of manufacturers do not seem to be able to make a reliable cylinder-head gasket, and in many cases they are several thousandths of an inch thinner between the valves and between the pairs of the cylinders than they are round the edge. The best gasket I have found is, unfortunately, one that is made in America.

The great difficulty in the use of cast-iron-headed valves is in obtaining supplies on a large scale. It is rather a tricky job to cast a head on a steel stem, and after trying nearly every source 
(Mr. O. W. J. Watson.)

of supply, I have come to the conclusion that the best type of valve is one of stainless steel, which stands up and gives wonderful results. The cast-iron-headed valve must also be heavier than a solid steel valve in order to obtain the necessary strength under the head, though they will stand up all right on low-speed engines, especially if the output is small so that they can receive personal supervision in the foundry. I have noticed that many paraffin vaporisers ane so complex in coring that the amount of scrap is very great, and I think it is very necessary for the designer of a vaporiser to keop in close touch with the foundry, and hear what the foundry foreman has to say.

The main thing about lubrication is to watch details. I think that either system is quite good, if the design of the details is very carefully gone into, and a certain amount of research work is carried out on each new design. I have noticed that a lubrication system which is quite satisfactory on one particular engine is quite unsatisfactory on another, so that it is a matter that ought to be dealt with individually for each type of engine. One of the biggest troubles in lubrication is due to the oil holes themselves. Small oil holes, say under $\frac{1}{8}$-in. diameter, are sure to give trouble, for they will get stopped up sooner or later. Another thing is that I do not think that sufficient care is taken in the shops to remove the burrs after drilling these holes, especially holes drilled in copper or steel pipes. If they are not removed the fluff and dirt in the oil will inevitably silt up round the projections and eventually cause the hole to be blocked up. As regards oil filters, the author states that they should be made easily removable while the engine is running. I think a very much better plan is to make them so large that they do not need to be examined, except at very long intervals when the boat is not in motion, because it is a very nasty job in a heary sea to have to take an oil filter out.

Captain C. E. Pope: I agree with Mr. Watson that die-cast white-metal bearings over $1 \frac{1}{2}$ in. diameter do get extruded unless there is a substantial gun-metal housing to hold the white-metal in. I cannot see the need for detachable heads for engines up to 100 h.p. when, by a little care in design, the piston and connecting rod can be taken out, and the combustion head cleaned fnom below. We have heard something about the difficulty of remaking joints, and I think the fewer joints there are in the cylinder the better. With regard to the impossibility of reaching some parts of a fixed head for decarbonising, I think that it is only a question of a suitable tool. I agree that the plunger pump has justified itself. It did so in the steam days, and I do not think we can do very much better than follow the lines on which many of the steam engineers worked. Reference has been made to casting valve heads on to the stems; while I do not agree with cast-iron heads, a good job can be made if the heads are screwed on to the stems. Valve-stem guides should invariably be bushed, 
but some makers are still casting the guides in the eylinders, which sooner or later have to be bored out and a valve guide put in. I think that for marine work it should be a sine qua non that valve stem guides should be of bronze, or some similar non-rusting material. The total enclosing of working parts may be a small point, but it is an important one, yet we still see the teeth of timing wheels on quite supposedly up-to-date makers' exhibits. The author has not touched upon the strength of starting gears, but I think it should be impressed on all makers of marine motors that this should be very ample.

Mr. E. B. WooD: I think the author is asking rather a lot of a paraffin vaporiser that it should run indefinitely at no load without any sort of auxiliary heat. The engine may run under these conditione owing to the high vacuum in the induction pipe lowering the boiling point of the fuel, but it is not likely to respond readily when the throttle is opened up. My own experience has been that the heat from the exhaust has hardly been sufficient to give good "opening up" with heavy petrols after prolonged no-load running at slow speed, in spite of the whole of the exhaust being diverted through the vaporiser jackets by a throttle in the exhaust pipe interconnected with the main throttle. The only sort of arrangement I have seen that looks as if it might be satisfactory in that respect is that which the Austin Co. used on some of their lighting engines, in which the vaporiser was actually incorporated in the valve cap, though I should not think it would be very. handy to get at for cleaning.

It is the practice in marine work for the cylinder to be supplied with cold water direct from the sea. I should think that in that case the paraffin, however well it is vaporised, is much more likely to be collected by the oil on the cylinder walls and so carried down into the base, than in the case, say, of agricultural tractors, in which the water is returned from the radiator at a fairly high temperature. I suppose. the real reason why so little trouble is experiencod in marine practice in this connection is that the bearing: pressures are so low that they can run satisfactorily on a very much diluted lubricating oil.

Mr. V. G. BARFoRD: I have been connected with paraffin vaporisers and their design for about twenty-five years, and have accumulated a certain amount of experience. Broadly put, it amounts to this, that in a parafin vaporiser it is necessary to have some adjustment of the heat. If it is so designed that it gets sufficient heat at little or no load, it will certainly get too much heat at full power, unless there is some method of by-passing. Another point is that the passages through which the mixture passes should be of such a size that the velocity is kept fairly high, otherwise pooling of the oil in the vaporiser will occur at light loads, with disastrous consequences when the throttle is opened up. In consequence of representations from our sales staff, we have many times during the past few years considered the ques- 
(Mr. V. G. Barford.)

tion of fitting reciprocating pumps, but have decided against them on account of the high speed at which the majority of our marine engines run, as this would involve a complicated construction which is far too expensive for the ordinary user. We find that in ases where a large amount of sandy and gritty water has to be dealt with, a centrifugal pump is hest if placed below, or at any rate on, the water line. The centrifugal pump has a great many advantages. It is the only pump which can really be throttled, and it will pass anything in the nature of grit, and will last, if properly designed, in gritty water, as long as any pump that has ever been proposed for the purpose. For ordinary usage, however, in our opinion, nothing can beat the ordinary drum pump, but it also. must, be placed low, say, not more than $1 \mathrm{ft}$. above the water line, and in the case of larger boats it should be fitted with a device for priming. It has the great advantage with high-speed engines that it can be run at either camshatt or crankshaft speed.

I was very pleased to hear Mr. Wood's reference to the coldness of the sea inlet, and the effect it has on the running of the engine. It seems to be very desirable with paraffin marine engines to provide some mothod of pump adjustment by means of which, when starting: up in the morning, or when running light, the amount of water can be reduced so that the heat in the engine can be maintained. There is no doubt at all that with a paraffin vaporiser it is necessary to have a fairly high jacket temperature. The difficulties with paraffin are immensely increased if large quantities of cold water are pumped in, but there is not the slightest difficulty in arranging matters so that the circulation can be very much reduced when required, but this should be done in such a way that it is impossible for the engineer to entirely cut off the circulation.

I may say that our experience with die-cast bearings is that they are perfectly, satisfactory for main bearings, in spite of the prejudice there is against them, but we do not recommend them for the big end of connecting rods, in which case white-metal should be run into a liner. It is, however, important, that the whole length of a die-cast bearing should be supported: It is also important that the outside of the shell should be a perfect fit in its housing. There is one defect of the shell lined with white-metal which is very difficult to guard against, and that is that the white-metal has so little mass that if it is not in perfecto metallic contact throughout it will run out at the slightest warming up before the heat can be conducted away. On the other hand, a die-cast bearing of fairly large diameter in itself, and properly fitted in its housing, has a bigger mass and is able to take up a very fair amount of heat without any risk of the surface running. We tried cast-iron-headed valves some time ago, and found that it properly made they are quite satisfactory, and will run for long periods without any attention at speads up to, say, 800 revs. per minute, but above that speed the heads break up. 
Mr. O. W. J. Watson: Did you cast the heads on?

Mr. BARFord: Yes, but we did not do it ourselves. They were bought from America. In the early days it used to be thought that separate cylinders ought to be provided as being cheaper ii replacements were required, but nowadays it seems to be agreed that cylinders should be cast in pairs. This certainly simplifies the water joints and the connections for inlet and exhaust.

My firm has, I believe, tried every system of lubrication that has been proposed. We have found no difficulty whatever with the forced lubrication system when properly installed, and when adequately provided with filters, which are cleaned periodically, and not when the trouble has occurred. If the filters are large, and the oil pump is submerged in the oil, there is no reason why the user should ever know that he has got a lubricating oil pump. What may be described as the pump-distributed splash system is also a very good and reliable one, and has been fitted to many of our engines with great success. We prefer, if possible, to make the whole supply visible, and we have tried both single and multiple indicators; in the latter case we had an indicator for every bearing. We had to drop it, however, on account of the large number of connections and the liability for dirt to get, into the system, which we found to be much greater than on a single visible overflow. I quite agree with the author as to the necessity for keeping the main bearings of forced-lubricationengines tight, and there is no type of engine in which it is easier to keep. them tight, and a good system of forced lubrication will maintain the bearings in such a condition that there should be practically. no wear. I agree with the author in his condemnation of Vernier couplings. A magneto should certainly be so fitted on a marine motor that it is impossible for it to be re-assembled in a different prsition from the original one, and the makers should fix the advance once and for all. Vernier couplings are only asked for by the testing departments and other experts in order to get the last ounce out of an engine by a slight alteration to the advances of the magneto. I was also glad to see that the author advocated a spare magneto in preference to dual ignition. The second ignition is usually out of order when it is badly wanted, whereas if a spare magneto is kept in a watertight bigg it oan be fitted in place in ten minutes or a quarter of an hour.

Mr. F. A. S. Acres: As far as my own experience goes, if the bearings of an engine are large enough for their work the splash system will give reliable lubrication. I can definitely say that if the bearings of a splash lubricated engine are examined they will show a lovely surface, but I have never seen a forcedlubrication engine yet in which the metal surface of the bearings did not look as if it had had some fine gritty substance rubbed into it. I always ascribe this to the fact that tiny bits of fine grit that will get through the finest filter that can be used for lubricating oil are being forced into the bearings along with the oil.

MACMILLAN. 
(Mr. F. A. S. Aares.)

I agree with Mr. Barford that the die-cast bearing is much less liakle to run than a bearing with only a thin white-metal lining in a shell, and certainly if a spare bearing is carried it is a much easier job to fit a die-cast bearing than try to run white-metal into a gun-metal housing. Presumably another white-metal-lined housing should be carried as well. The gear-wheel type of pump for water circulation does oertainly wear badly, and I have seen some extraordinary shaped teeth after one of these pumps had been running for a comparatively short time in shallow water. I should certainly myself prefer the plunger pump, for it will keep running even if not at its best, and that is more reliable than a pump which will give out altogether. I entirely agree with what the author has said on Vernier couplings.

Mr. R. G. L. Mariman: I think that nine-tenths of the troubles with gear pumpis are due to the fact that they are installed at too great a height above the water line without any arrangement for priming. I agree with Mr. Wood and Mr. Barford that trouble is often experienced with a marine motor simply because too much water is pumped in and the jacket temperature is too low. After all, the internal combustion engine is a heat engine and it should not be run cold.

Mr. LitTLEwood: When I was connected with the Service, we had an engine which had ralves with cast-iron heads, but these brcke and did damage to the extent of $£ 50$. The extra aost of fitting steel valves would have been more than covered if they would have prevented this accident. In my opinion, the heating lamps. which the author condemns, are very efficient. They ensure a constant temperature under all conditions and sufficient heat to vaporise the fuel passing through to the cylinder. Mr. Barford said that die-cast bearings should be fitted into their housings. l know of a transport firm which adopted the practice of having their bearings bedded in the crankcase with special care, and it was found that the time between overhauls was increased by 33 per cent. If that can be done in lorry work, it should prove equally satisfactory in marine work.

Mr. S. C. SAUNDERS: The author says the engine "should be supported on longitudinal bearers," but I think it is better to have the engine and reversing gear lined up on separate angle iron bearers fixed down on the top of the wooden ones, so that any tendency for the wood to warp or of the hull to distort will not affect the alinement of the engine. I cannot agree with the author in regard to die-cast bearings. My experience has been that a properly designed gun-metal shell and a white-metal lining is the most efficient in the long run. In all the engines I have dealt with, it has been the practice to drill holes completely through the shell and run the white-metal through these holes, thus forming a compact arrangement with the shell itself. I should like to know what type of rubber ring the author has tried for the joints in the cylinder head, because rubber ring joints are uni- 
rersally used with Diesel engines and prove entirely satisfactory. The type of ring is not of round section, but of square or V-shaped section fitting a specially shaped groove and this will successfully hold any pressure that is put on the water jacket. I think that the camshaft should be arranged so that it can be withdrawn lengthwise without dismantling the whole engine. I have seen very successful valves in which the cast-iron head has been electrically welded on to the steel stem. There are various types of paraffin vaporisers in which the heat supply is regulated by a hand-controlled by-pass, but that, of course, cannot be satisfactory. under all conditions. My experience has proved that the most satisfactory plug to use in paraffin engines is the porcelain one. With mica-insulated plugs there is a great tendency to shortcircuit between the layers of mica should any paraffin reach them.

Mr. BasIL H. Joy: On the whole, I am in very full agreement with the author, and in my opinion the engines designed by him are among the most practical marine engines on the market tomday. One great difficulty is that the ordinary designer does not seem to appreciate that a marine engine is not fitted conveniently in the same way as on the test bench, when everything: is accessible, but is bedded down on to bearers which extend both forward and aft beyond the engine and up to the level of the centre line of the shaft, so that nothing below that line can be got at at all. Valve springs should certainly be covered in, as this not only protects them from rust and tends to reduce noise, but keeps them well lubricated. Whatever arrangement is made, however, the cover should be removable by taking off nothing more than a single butterfly nut, and no spanner should be required. In my opinion, based upon actual experience, the ordinary cast-iron valve cap with a comparatively shallow hexagon head is perfectly useless for marine work, as the combined effect of the heat and the sea air wastes them away and a spanner will not grip them, in fact quite recently I had to chip one out! Again, the adjusting nuts on the tappets are very much too thin, and I cannot see why they cannot either be made thicker or be made with some sort of holding device which would not get in the way of the spanner while turning the lock nut. The valve spring cotter is an exceedingly elusive little thing, very hard to get out, very hard to get back and very liable to drop into the bilges. Here, again, I cannot see why it should not have something in the nature of a handle to it so that it can be drawn out or replaced without the neod of a special pair of pliers. I am sure it is worth a little thought, because it is these little things which worry the boat owner and make him neglect jobs he ought to do. The author has suggested that the contact breaker should be vertical. I am glad to see that there is an engine in the Show which actually has a vertical armature spindle so that the contact breaker is on the top and clearly in view. It is obviously the ideal arrangement, and I do not know why it has not been done before. I am afraid I am no 
(Mr. Basil H. Joy.)

lover of these little pumps for lubricating oil-usually placed in inaccessible positions and which will probably work satisfactorily for: 364 days out of the year but on the 365 th it goes wrong suddenly, and the first intimation of trouble is the labouring of the engine. I have taken my own lubricating pumps off altogether, and have reverted to simple splash lubrication, which 1 find more satisfactory as I know it will want attention and it gets it. The little oil pump deceives by its very reliability, which aauses it to be neglected. At the same time I would very much prefer to have a trough system fed by the flywheel as carried out by the author. I cannot conceive of arything simpler or more reliable. I can never fathom the reason why there is no provision for cleaning all the contaminated oil out of the cranlicase other than a plug fitted somewhere away under the engine. It is not an easy thing to devise, but I really think that it is worth some further thought. Marine motor designers must realise the importance of easy starting. This operation often has to be performed in a cramped or awkward position and possibly in a lump of a sea too. I should be rather afraid that the objections which the author has raised to the impulse starter afloat have a good foundation. It is very difficult to get these small mechanical devices to stand up to the corroding effects of sea water, but if that difficulty can be overaome there is no doubt about their value. I cannot, however, quite agree with the author and others in their sweeping condemnation of accumulator ignition on the ground that it will be neglected. If it is used simply as a standby, that may be true, but if it is used regularly for starting up, it will only need a single instance of neglect and reversion to starting by magneto to ensure better attention in the future. I have got a 6-volt accumulator coupled through a three-way switch with the earth terminal on the magneto, and this ensures easy starting with generally not more than two pulls up on the handle, so that I take good care that the accumulators are kept in condition.

Mr C. H. Macmillan, in replying on the discussion, said: An engine in which the bearing pressures are very high is an overloaded engine, and the fact that an engine is overloaded wili, of course, create vibration. If, however, the stationary parts of the engine, the crankcase, the reversing gear, ete., constitute a large proportion of the total weight, while the moving parts are as light as possible, then vibration will be very much reduced. Mr. E. Pope suggested the possibility of removing the piston and connecting rod from the bottom and cleaning the combustion head through the crankcase door, but in a cylinder of $5 \mathrm{in}$. bore it will be found almost impossible to make a thorough job of cleaning the head in this way owing to the length from the crankpit to the combustion chamber. It is true that copper and asbestos gaskets for the cylinder head do vary in thickness. but if the head has a sufficient number 
of studs and is in itself sufficiently rigid to keep flat, I do not think any trouble should be experienced with the joint. A rubber ring is best for the water joint, and this should be a plain circular ring rather like a piece of ordinary water hose about half an inch in length and of a diameter to suit the flow of water. If the recesses in the cylinder and head are so arranged that the rubber is compressed a little before the pressure comes on the copper-asbestos joint, the water will never reach the asbestos. The joints are, of course, square ended. I agree with Mr. Acres that the pressure-fed bearing takes on quite a different appearance from the pure glassy surface of the splash-or gravity-lubricated-bearing. I presume that this is due to the very finely divided impurities or solid matter in the oil being forced on to the surface and rubbed into it, whereas with splash lubrication any light matter such as fluff will float off and probably will not reach the bearing at all; in any case, it would not be forced through in such great quantities as with the pump. The whole secret of success with die-cast bearings is that they should be properly fitted in the casing or connecting-rod, as the case may be, in order to get a good bearing-surface right across. If shims are fitted they should be fairly stiff plates, not thin and flexible. In engines up to $100 \mathrm{~h} . \mathrm{p}$. I would use plates in the neighbourhood of $\frac{1}{4}$ in. thick, and if die-cast white-metal bearings are fitted in such a way that there is a good pressure on the edges pressing the halves of the bearing firmly into their housing, I do not think any trouble will be experienced. It is quite true that white-metal is liable to be extruded, but only if the bearing is overloaded, and sufficient surface should be provided to prevent excessive pressures. Then if the engine runs short of oil and the bearing warms up, the white-metal tends to become plastic, which soon leads to an increase in the clearance between the shaft and the bearing which allows it to free and cool down provided oii is then supplied. The quality of the metal, of course, has a good deal to do with this. As a rule, a harder quality metal is used for die-cast bearings than for lining gun-metal bearings, and the plasticity which this gives over a considerable range of temperature is of great assistance in preventing them from running completely out.

If cast-inon is used for valve-heads, the stem should be screned into the head and riveted over to prevent any chance of its unscrewing, while the boss on the head should be extended well down over the threads so as to prevent the hot gases impinging on them. The principal points in which a marine engine differs from a motor car engine are that the latter is generally repaired and overhauled from below, whereas the former is repaired from above, that the motor car engine is subjected to varying loads, whereas a marine engine has to be capable of doing full load. continuously, and that the motor car engine has a good draught of cold air rushing past the crankcase which 
(Mr. C. H. Macmillan.)

thoroughly cools the oil, and that gives it a great adrantage over the marine engine, which is in an engine room or a box and gets no draught of cold air at all. It is, in fact, certainly desirable to fit an oil cooler, especially in the larger sizes, as this not only keeps the oil in better condition but leads to economy in the use of oil. In high-speed engines a rotary pump is probably as suitable as a plunger pump, but $I$ think the plunger pump will hold it own for a long time to come owing to the fact that it is as nearly absolutely reliable as can be. The most likely cause of trouble is the sticking of a valve owing to dirt, but a properly designed filter ought to prevent the entry of any foreign matter sufficiently large to jamb a properly designed valve. In connection with the temperature of the water in the cylinder jackets, I stated in the paper that ample water spaces should be provided everywhere round the cylinders, valves and valve passages, designed in such a way as to prevent the formation of steam pockets, and it that is done a smaller quantity of water can safely be passed through the engine and kept an a fairly high temperature. By this means the walls of the cylinders will be kept sufficiently cool and yet the water round the combustion chamber will not be so cool as to cause undue condensation of the paraffin in the cylinder. I had intended to say a great deal more about vaporisers than I did, but the length of the paper had to be limited. In a paraffin engine the vaporiser offers as much scope for discussion as all the rest of the engine. I do not agree with $\mathrm{Mr}$. Barford that the by-rassing of the exhaust is necessary to accommodate varying lceds. So long as only a very small proportion of the air and all the fuel is passed through the heating chamber at full load, and all the mixture goes through it at no load, and also that the whole of the vaporisation takes place under the reduced racuum between the throttle and the engine, then satisfactory vaporisation can be obtained at widely varying loads without a by-pass on the exhaust. Mr. Barford also mentioned the desirability of maintaining fairly high velocitias in the vaporiser passages to avoid pooling of the oil, but surely the best way of avoiding this is to avoid having. places where the oil can pool. I agree with Mr. Saunders that mica plugs are not so suitable for paraffin engines as plugs with porcelain or steatite insulation. 


\section{COMMUNICATIONS.}

Mr. J. L. MILLER wnote: Some designers do not realise, as the author does, the need for a little care in the choice of magneto position, in the coupling selected, and in the method of fixing: "The magnetio must not be placed too near hot exhaust pipes." I have known magnetos working successfully at $180^{\circ} \mathbf{F}$., but the insulation on the armature is likely to become brittle and unreliable with long use at high temperature.

There is another disadvantage which is seldom realised, namely, that high temperatures increase the resistance of the winding: and seriously affect the efficiency of the magneto. For instance, one machine which was found to spark at 100 revs. per minute over a $5.5 \mathrm{~mm}$. gap at $60^{\circ} \mathrm{F}$. required 200 revs. per minute to enable it to give the same spark when heated to $190^{\circ} \mathrm{F}$. This may be one of the causes of difficult starting when the engine is hot.

"The coupling should have a minimum number of wrong ways." It should also be flexible and easily alined. Steel to steel couplings, new and perfectly fitted, are quite satisfactory, but when worn or out of alinement they subjeat the armature to a continuous succession of blows like an impact test.

Agrain, it is a common thing to see a magneto mounted on a cast iron base with iron straps rising from the base and encircling the magneto, thus forming a magnetic short circuit. A strap of quite moderate dimensions can thus easily reduce the spark energy by 30 per cent. Early magnetos had sometimes as many as six magnets. To-day, equal results are obtained with one, but it is essential that this one be given fair treatment. The loss by bolting the magneto to an iron base is slight, as the magnet is usually about $\frac{3}{4}$ in. from the base, but, if this is bridged by an inon strap, difficult starting is practically certain. This magnetic leakage cannot be prevented by the insertion of a strip of fibre or other electrical insulation. If a strap is used under such circumstances, it should be of brass or other non-magnetic material.

Mr. G. SteinheIl wrote: Designers must realise that the majority of small marine engines are attended by unskilled or semi-skilled labour, and therefore have to be designed accordingly. Yet these engines are often fitted with many little hand adjustments, and these the drivers seem to take a particular delight in "improving." It seems to be no use to tell them not to touch. The only way out of it is to ramove the temptation by striking: a compromise in the design. I would suggest that between $20 \mathrm{~h}$.p. and $60 \mathrm{~h} . \mathrm{p}$. the engine should have the cylinders and upper part 
(Mr. G. Steinheil.)

of the crankcase cast in one block, the lower part of the crankcase being an ordinary marine bedplate resting on strong longitudinal bearers, and having the reverse gear and thrust block rigidly. bolted to it. The three main bearings should be interchangeable with the big ends; large easily-detachable but oil-tight inspection doors should be fitted to the top part of the crankcase. 'The engine should be of the heavy-duty slow-speed type (350-600 revs. per minute, according to size) in which case the inertia forces would be comparatively low and a mild steel crankshaft might be used.

The cylinder-heads must be detachable in one piece for all the cylinders. By this means the number of nuts to be unscrewed when taking off the cover for cleaning purposes will be reduced to a minimum. All the valves should be in the cylinder-head, actuated from an overhead camshaft driven from a vertical shaft. The whole of the valve gear should be enclosed in a water-tight casing. This arrangement may look complicated and expensive at first sight, but it possesses many obvious advantages, and the camshaft can be so designed as to be easily detachable. The valves can be conveniently ground in without any fear of grit and emery powder getting inside the cylinders. The magneto and the lighting dynamo, encased in water-tight covers, can be driven from the vertical shaft.

Hand starting in conjunction with an impulse magneto coupling has many advantages over the eleotric starting system, as with the latter an inexperienced driver can easily run the battery out. I am against dual ignition because it so often happens that when the magneto fails the battery is found to be out of order. When the driver knows that he has only the magneto to rely upon, he takes good care to keep it in working order, knowing that ignition failure in a heavy sea or rapid river may perhaps cost him his life. To facilitate hand starting, screw-down compression-release taps can be fitted in the cylinders half way down the cylinder bore. For lubrication of marine engines of the type outlined, a gravity drip-feed from an oil tank placed above the engine is probably the most simple and reliable arrangement. The sightfeed ought to have glass protection, and the adjusting screws must be of ample dimensions and provided with good lock nuts. The oil piping for the main bearings should be of fairly large bore ( $\frac{1}{2}$ in.) and screwed into the bearing caps to get the benefit of the head in the pipe. Centrifugal thrower rings may be used for the lubrication of crank pins at these speeds. In the smaller engines, splash may be relied upon for lubricating the gudgeon-pin and cylinders, but on larger sizes a special oil feed should be arranged, and the sump should be water cooled.

More attention should be given to the design of paraffin vaporisers, which should give at least the same power output per cylinder as petrol, and work without undue smoke on light loads. Paraffin engines have, of necessity, to be slower-running than 
petrol engines, because paraffin takes a certain amount of time t $J$ vaporise, and the slower the speed the better can be the vaporisation.

The author mentioned that the whole design of marine engines is a matter of compromise between various requirements, and therefore it may be preferable to have a heavier engine requiring little attention than a very light one with a heavy maintenance bill.

In reply to the written communications, Mr. Macmillan wrote: $\mathrm{Mr}$. Steinheil appears to be entirely in agreement with the opinions expressed in the paper regarding simplicity of operation and absence of complications which have to be understood by the users. He suggests casting the cylinders and the top half of the crankcase in one piece. While I quite agree that this may be advantageous in small engines up to, say, $20 \mathrm{~h} . \mathrm{p}$., I think the risk involved in doing so with a slow-speed $50 \mathrm{h.p}$. engine is very great, and the expense of renewal which may be caused by some trivial breakage will amount to a considerable proportion of the total value of the engine. The weight of a cylinder unit in a large engine would also be objectionable. So long as the cylinders are all cast en bloc I think the overhead camshaft is admissible, but when the cylinders are in pairs or single, the difficulties involved render this system undesirable.

I think something much more automatic than drip-feed lubrication is required for use in unskilled hands. It gives the drivers too much scope for "improving" the lubrication. If an oil pump is to be fitted as suggested, then a properly designed splash system is much better in unskilled hands.

Regarding vaporisers, I think Mr. Steinheil is a little too ambitious, as it is difficult to see how the same results can be expected from paraffin as from petrol, owing to the inherent differences between the two fuels, the heavier fuel requiring. higher inlet temperature and possessing a greater tendency to detonate, both of which properties operate to its detriment when compared with the lighter fuel. My experience has been that the results from the higher-speed paraffin engines approach more nearly to those from the equivalent petrol engines than is the ase with the slow-speed engines. 